\title{
Simulation of Chaotic Oscillators of Fractional Order
}

\section{Simulación de Osciladores Caóticos de Orden Fraccional}

\author{
SILVA-JUÁREZ, Alejandro†*, SALAZAR-PEDRAZA, Miguel De Jesús, PONCE-MELLADO, Juan \\ Jorge and HERRERA-SÁNCHEZ, Gustavo
}

Universidad Tecnológica de Puebla

ID 1 $1^{\text {st }}$ Author: Alejandro, Silva-Juárez / ORC ID: 0000-0001-8473-9803, Researcher ID Thomson: F6969-2018, arXiv Author ID: Alejandro_Silva, CVU CONACYT ID: 637028

ID $1^{\text {st }}$ Coauthor: Miguel De Jesús, Salazar-Pedraza / ORC ID: 0000-0001-9210-1930, Researcher ID Thomson: Q-98582018, arXiv Author ID: EduCIBEL, CVU -615713

ID $2^{\text {nd }}$ Coauthor: Juan Jorge, Ponce-Mellado / ORC ID: 0000-0003-2186-2868, arXiv Author ID: Jorge_Ponce, CVU CONACYT ID: 900658

ID $3^{\text {st }}$ Coauthor: Gustavo, Herrera-Sánchez / ORC ID: 0000-0001-5276-5062, Researcher ID Thomson: F-6595-2018, arXiv Author ID: herreragh, CVU CONACYT ID: 459805

DOI: $10.35429 /$ EJT.2019.6.3.11.17

Received October 22, 2019; Accepted December 11, 2019

\begin{abstract}
In 1695 the theory of fractional calculus was introduced, but it only developed as a pure mathematical branch. Currently several research groups have focused on the control, the implementation of filters, PID controllers, synchronization, the implementation of circuits of chaotic systems of fractional order, etc. Currently, the number of applications of fractional calculus is increasing rapidly, these mathematical phenomena have allowed us to describe and model a real object more accurately than the classical "integer" methods. Along with the development of the fractional calculation, it was shown that many fractional-order nonlinear dynamic systems behave in a chaotic manner. This is the type of non-linear systems that are addressed in this research topic with the focus on derivatives of arbitrary order, where numerical simulations of chaotic behavior are presented in nonlinear, fractional-order autonomous models. The case studies are six chaotic oscillators of fractional order; The systems of Lorenz, Rössler, Financiero, Lui, Chen and Lü, whose attractors are obtained by applying the definitions of the Grünwald-Letnikov definitions and the predictive corrective method of Adams-Bashforth-Moulton.
\end{abstract}

Caos, Sistemas de orden fraccional, Osciladores

\section{Resumen}

En 1695 se introdujo la teoría del cálculo fraccional, pero solo se desarrolló como una rama matemática pura. Actualmente varios grupos de investigación se han enfocado en el control, la implementación de filtros, controladores PID, la sincronización, la implementación de circuitos de sistemas caoticos de orden fraccional, etc. En la actualidad, el número de aplicaciones de cálculo fraccional crece rápidamente, estos fenómenos matemáticos han permitido describir y modelar un objeto real de manera más precisa que los métodos clásicos "enteros". Junto con el desarrollo del cálculo fraccional, se demostró que muchos sistemas dinámicos no lineales de orden fraccionario se comportan de manera caótica. Este es el tipo de sistemas no lineales que se abordan en este tema de investigación con el enfoque en las derivadas de orden arbitrario, donde se presentan las simulaciones numéricas del comportamiento caótico en modelos autónomos no lineales de orden fraccional. Los casos de estudio son seis osciladores caóticos de orden fraccional; Los sistemas de Lorenz, Rössler, Financiero, Lui, Chen y Lü, cuyos atractores se obtienen aplicando las aproximaciones de las definiciones de Grünwald-Letnikov y el método predictor corrector de Adams-BashforthMoulton.

Chaos, Fractional order systems, Oscillators

\footnotetext{
* Correspondence to Author (Email: alejandro.silva@utpuebla.edu.mx)

$\dagger$ Researcher contributing as first author.
} 


\section{Introduction}

With the development of fractional calculus and chaos theory, chaotic systems of fractional order have become a subject of study to assess their characteristics, design them with analog and digital electronics, and propose applications [1]. Models of fractional order systems allow describing and modeling a real object more accurately than using classic "integer" methods.

The biggest difference between the models of fractional orders and of whole order is that those of fractional order depend on the history of the system, since they have memory [2]. That is why traditional numerical methods must adapt or propose new methods to simulate oscillators of fractional order [3-7].

\section{Approximation of fractional order systems}

Fractional calculation is a generalization of integration and differentiation to the fundamental operator of non-integer order ${ }_{a} D_{t}^{q}$ described in (1), where a and $t$ are the limits of the operation and $q \in R$. In this way, the numerical calculation of the derivatives of fractional order are made with approximations and in this work the definition of GrünwaldLetnikov (G-L) $[1,3]$, described in (2) is applied,

$$
\begin{gathered}
{ }_{a} D_{t}^{q}= \begin{cases}\frac{d^{q}}{d t^{q}}, & \mathrm{q}>0, \\
1, & \mathrm{q}=0, \\
\int_{a}^{t}(d \tau)^{q}, & \mathrm{q}<0 .\end{cases} \\
\left(k-L_{m} / h\right) D_{t_{k}}^{q} f(t) \approx \frac{1}{h^{q}} \sum_{j=0}^{k}(-1)^{j}\left(\begin{array}{l}
q \\
j
\end{array}\right) f\left(t_{k-j}\right)
\end{gathered}
$$

Where $L_{m}$ is the memory length, $t_{k}=$ $k h, \quad h$ is the step size of the calculation and $(-1)^{j}\left(\frac{q}{j}\right)$ are the binomial coefficients denoted by $c_{j}^{(q)}(j=0,1, \ldots)$. The following expression can be used for its calculation [4]:

$c_{0}^{(q)}=1, c_{j}^{(q)}=\left(1-\frac{1+q}{j}\right) c_{j-1}^{(q)}$

Then, the general numerical solution of the fractional differential equation ${ }_{a} D_{t}^{q} y(t)=$ $f(y(t), t)$, can be expressed as

$y\left(t_{k}\right)=f\left(y\left(t_{k}\right), t_{k}\right) h^{q}-\sum_{j=v}^{k} c_{j}^{(q)} y\left(t_{k-j}\right)$
For the term of memory expressed by the summation, the principle of "short memory" can be used. Then the lower index of the sums in the relationships (4) will be $v=1$ for $k<\left(L_{m} / h\right)$ y $v=k-\left(L_{m} / h\right)$ for $k>\left(L_{m} / h\right)$, or without using the principle of short memory, $\mathrm{v}=1$ is made for all $\mathrm{k}$.

Obviously, truncating the memory length implies an inaccuracy. If $f(t) \leq M$, The following estimate can be established to determine the memory length $L_{m}$, providing the required accuracy $\varepsilon$ :

$L_{m} \geq\left(\frac{M}{\varepsilon \mid \Gamma(1-q \mid}\right)^{1 / q}$

An evaluation of the effect of short memory and the convergence ratio of error between short and long memory are described in [7].

For the numerical simulation of the fractional order system, a method based on the predictor-corrector scheme of type ABM [4] has also been proposed, the method is based on the fact that the fractional differential equation $D_{t}^{q} y(t)=f(y(t), t), y_{0}^{(k)}, k=0,1, \ldots, m-1 \quad$ is equivalent to the integral volterra equation

$y(t)=\sum_{k=0}^{[q]-1} y_{0}^{(k)} \frac{t^{k}}{k !}+\frac{1}{\Gamma(q)} \int_{0}^{t}(t-\tau)^{q-1} f(\tau, y(\tau)) d \tau$.

Discretizing (6) to $t_{n}=n h(n=$ $0,1, \ldots, N), h=T_{\text {sim }} / N$ and using the principle of short memory as in [8] the numerical approximation of the solution is obtained $y\left(t_{n}\right)$ and the order of precision is preserved. The corrective scheme is shown in (7).

$$
\begin{aligned}
& y_{h}\left(t_{n+1}\right)=\sum_{k=0}^{m-1} \frac{t_{n+1}^{k}}{k !} y_{0}^{(k)}+\frac{h^{q}}{\Gamma(\alpha+2)} f\left(t_{n+1}, y_{h}^{p}\left(t_{n+1}\right)\right) \\
& +\frac{h^{q}}{\Gamma(\alpha+2)} \sum_{j=0}^{n} a_{j, n+1} f\left(t_{j}, y_{n}\left(t_{j}\right)\right)
\end{aligned}
$$

\section{Where}

$$
\begin{aligned}
a_{j, n+1} & =\left\{\begin{array}{l}
n^{q+1}-(n-q)(n+1)^{q}, \\
(n-j+2)^{q+1}+(n+j)^{q+1}+2(n-j+1)^{q+1}, \\
1,
\end{array}\right. \\
a_{j, n+1} & =\left\{\begin{array}{l}
\text { si j=0, } \\
\text { si } 1 \leq j \leq n, \\
\text { si j=n+1. }
\end{array}\right.
\end{aligned}
$$


As shown in [1], both numerical methods described in the time domain; GL and ABM have approximately the same order of precision and a good match of numerical solutions.

\section{Fractional Systems Stability}

The stability of nonlinear systems of fractional order is very complex and different from the linear system of fractional order [3]. The main difference is that, for a non-linear system, it is necessary to investigate the stationary states by evaluating (5), that is, the system's equilibrium points $E^{*}=\left(x_{1}^{*}, x_{2}^{*}, x_{3}^{*}\right)$.

$$
{ }_{a} D_{t}^{q} f(t)=f(x)=0
$$

According to the stability theorem defined in [8], the equilibrium points are asymptotically stable for a commensurate system, that is $q_{1}=q_{2}=q_{3}=q_{n} \equiv q$ if all own values $\lambda_{1},(i=1,2, \ldots, n)$ of the Jacobian matrix $J=\partial f / \partial x$, where $f=\left[f_{1}, f_{2}, \ldots, f_{n}\right]^{T}$, evaluated at break-even points $E^{*}$, satisfies the condition [10]:

$$
|\arg (\operatorname{eig}(J))|=\mid \arg \left(\lambda_{i} \mid>q \frac{\pi}{2}, i=1,2, \ldots, n .\right.
$$

To determine the stability of a fractional order system considered immeasurable, that is $q_{1} \neq q_{2} \ldots \neq q_{n}$ and assuming that $\mathrm{m}$ is the LCM of the denominators $u_{i}$ of $q_{i}$, where $q_{i}=v_{i} / u_{i}$, $v_{i}, u_{i} \in Z^{+}$for $i=1,2, \ldots, n$ and $\gamma=1 / m$, the system is asymptotically stable if $|\arg (\lambda)|>$ $\gamma \frac{\pi}{2}$. For all the roots of $\backslash$ lambda in the following equation

$$
\operatorname{det}\left(\operatorname{diag}\left(\left[\lambda^{m q_{1}} \lambda^{m q_{2}} \ldots \lambda^{m q_{n}}\right]\right)-J\right)=0
$$

The condition for systems derived from an immeasurable order is

$q>\frac{2}{\pi} \operatorname{atan}\left(\frac{\left|\beta_{i}\right|}{q_{i}}\right), i=1,2$

This condition can be used to determine the minimum order for which a nonlinear system can generate chaos [10].

\section{Simulation of Chaotic Attractors}

In this work the chaotic systems of fractional order of: Lorenz (15), Rössler (16), Financial (17), Lui (18), Chen (19) and Lü (20) are calculated and simulated.
Where $x, y, z$ are the state variables and $0<q_{1}, q_{2}, q_{3}<1$ It is the fractional order. The systems are represented by nonlinear differential equations because they present multiplication of variables in one or more equations.

$$
\begin{aligned}
& \left\{\begin{array} { l } 
{ D ^ { \alpha _ { 1 } } x = \sigma ( y - x ) , } \\
{ D ^ { \alpha _ { 2 } } y = x ( \rho - z ) - y , } \\
{ D ^ { \alpha _ { 3 } } z = x y - \beta z , }
\end{array} \quad \left\{\begin{array}{l}
D^{\alpha_{1}} x=-y-z, \\
D^{\alpha_{2}} y=x+a y, \\
D^{\alpha_{3}} z=b+z(x-c)
\end{array}\right.\right. \\
& \text { (15) } \\
& \text { (16) } \\
& \left\{\begin{array} { l } 
{ D ^ { \alpha _ { 1 } } x = z + x ( y - a ) , } \\
{ D ^ { \alpha _ { 2 } } y = 1 - b y - | x | , } \\
{ D ^ { \alpha _ { 3 } } z = - x - c z , }
\end{array} \quad \left\{\begin{array}{l}
D^{\alpha_{1}} x=-a x-e y^{2}, \\
D^{\alpha_{2}} y=b y-k x z, \\
D^{\alpha_{3}} z=-c z+m x y,
\end{array}\right.\right. \\
& \text { (17) } \\
& \text { (18) } \\
& \left\{\begin{array} { l } 
{ D ^ { \alpha _ { 1 } } x = a ( y - x ) , } \\
{ D ^ { \alpha _ { 2 } } y = c x - a x - x z + c y , } \\
{ D ^ { \alpha _ { 3 } } z = x y + b z , }
\end{array} \left\{\begin{array}{l}
D^{\alpha_{1}} x=a(y-x), \\
D^{\alpha_{2}} y=x z+c y, \\
D^{\alpha_{3}} z=x y-b z,
\end{array}\right.\right.
\end{aligned}
$$

\begin{tabular}{|c|c|c|}
\hline & Balance points & Own values \\
\hline$(1)$ & $\begin{array}{l}E_{1}=(0,0,0), \\
E_{2}=(\sqrt{(\beta \rho-\beta)}, \sqrt{(\beta \rho-\beta)}, \rho-1), \\
E_{3}=(-\sqrt{(\beta \rho-\beta)},-\sqrt{(\beta \rho-\beta)}, \rho-1)\end{array}$ & $\begin{array}{l}\lambda_{1} \approx-13.8546, \lambda_{2,3} \approx 0.0940 \pm 10 \\
\lambda_{1} \approx-13.8546, \lambda_{2,3} \approx 0.0940 \pm 10 \\
\lambda_{1} \approx-22.82776, \lambda_{2} \approx 11.8277 \\
\lambda_{3} \approx-2.6667\end{array}$ \\
\hline (2) & $E_{1,2}=\left(\frac{c \pm \sqrt{c^{2}-4 a b}}{2},-\frac{c \pm \sqrt{c^{2}-4 a b}}{2 a}, \frac{c \pm \sqrt{c^{2}-4 c}}{2 a}\right.$ & $\begin{aligned} \lambda_{1} & \approx 0.47595 \\
z b & \lambda, 30.007017 \pm 4.57910 j \\
\lambda & \approx-9.98800 \\
\lambda_{2,3} & \approx 0.249007 \pm 0.96808 j\end{aligned}$ \\
\hline (3) & $\begin{array}{l}E_{1}=(0,1 / b, 0), \\
E_{2}=(\sqrt{(c-b-a b c) / c},(1+a c) / c,-(1 / c) \sqrt{(c-b-a b c}) \\
E_{3}=(-\sqrt{(c-b-a b c) / c},(1+a c) / c,(1 / c) \sqrt{(c-b-a b c)}\end{array}$ & 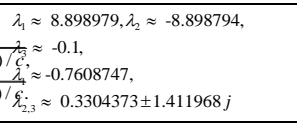 \\
\hline (4) & $\begin{array}{l}E_{1}=(0,0,0) \\
E_{2}=(\sqrt{(b c /(h k)}, \sqrt{(b c /(h k)}, b / k) \\
E_{3}=(-\sqrt{(b c /(h k)},-\sqrt{(b c /(h k)}, b / k)\end{array}$ & $\begin{array}{l}\lambda_{1}=-1, \lambda_{2}=-5, \lambda_{3}=-5, \\
\lambda_{1} \approx 4.387767, \\
\lambda_{2,3} \approx 0.4438837 \pm 3.346383 j .\end{array}$ \\
\hline (5) & $\begin{array}{l}E_{1}=(0,0,0), \\
E_{2}=(\sqrt{b(2 c-\mu}, \sqrt{b(2 c-\mu)}, 2 c-\mu), \\
E_{3}=(-\sqrt{b(2 c-\mu},-\sqrt{b(2 c-\mu)}, 2 c-\mu) .\end{array}$ & $\begin{array}{l}\lambda_{1}=-3, \lambda_{2} \approx 23.8359, \lambda_{3}=-30.8359, \\
\lambda_{1} \approx-18.4280, \\
\lambda_{2,3} \approx 4.2140 \pm 14.8846 \mathrm{j}, \\
\lambda_{1}=-18.4280 \\
\lambda_{2,3} \approx 4.2140 \pm 14.8846 \mathrm{j},\end{array}$ \\
\hline (6) & $\begin{array}{l}E_{1}=(0,0,0) \\
E_{2}=(\sqrt{b c}, \sqrt{b c}, c) \\
E_{3}=(-\sqrt{b c},-\sqrt{b c}, c)\end{array}$ & $\begin{array}{l}\lambda_{1}=-3, \lambda_{2} \approx 20, \lambda_{3}=-36, \\
\lambda_{1} \approx-22.6516, \lambda_{2,3} \approx 1.8258 \pm 13.6887 j, \\
\lambda_{1} \approx-22.6516, \lambda_{2,3} \approx 1.8258 \pm 13.6887 j,\end{array}$ \\
\hline
\end{tabular}

Table 1 shows the equilibrium points and their corresponding eigenvalues for stability analysis of the 6 chaotic systems of fractional order, where it is verified that, based on the signs of the eigenvalues and if they correspond to real or imaginary, it is observed that all the systems present asymptotic instability, chair node, chair focus, which are necessary to generate chaotic behavior.

Table 1 Balance points and their corresponding own values

Next, we describe the way in which the Lorenz fractional system (15) is adapted to obtain the numerical solution of the system by applying the definition of Grünwald-Letnikov, similarly it is done for the other systems that are analyzed in this work

SILVA-JUÁREZ, Alejandro, SALAZAR-PEDRAZA, Miguel De Jesús, PONCE-MELLADO, Juan Jorge and HERRERA-SÁNCHEZ, Gustavo. Simulation of Chaotic Oscillators of Fractional Order. ECORFAN Journal-Taiwan. 2019 
$x\left(t_{k}\right)=\left(\sigma\left(y\left(t_{k-1}\right)-x\left(t_{k-1}\right)\right)\right) h^{q 1}-\sum_{j=v}^{k} c_{j}^{\left(q_{1}\right)} x\left(t_{k-j}\right)$,

$y\left(t_{k}\right)=\left(x\left(t_{k}\right)\left(\rho-z\left(t_{k-1}\right)\right)-y\left(t_{k-1}\right)\right) h^{q_{2}}$

$$
-\sum_{j=v}^{k} c_{j}^{\left(q_{2}\right)} y\left(t_{k-j}\right)
$$

$z\left(t_{k}\right)=\left(x\left(t_{k}\right) y\left(t_{k}\right)-\beta z\left(t_{k-1}\right)\right) h^{q_{3}}-\sum_{j=v}^{k} c_{j}^{\left(q_{3}\right)} z\left(t_{k-j}\right)$.

Where $T_{\text {sim }}$ is the simulation time, $k=$ $1,2,3, \ldots, N$, for $N=\left[T_{\operatorname{sim}} / h\right]$, and initial conditions $\quad x(0), y(0), z(0) . \quad$ Binomial coefficients $c_{j}^{\left(q_{1}\right)}, \forall i$ They are calculated according to the relationship (3). To determine the minimum order of the fraction for which the Lorenz system is chaotic with the parameters $(\sigma, \rho, \beta)=(10,28,8 / 3)$ the relationship (14) is used. In this case the minimum order commensurate for $q_{1}=q_{2}=q_{3}$ is $q>0.9941$. In the case of immeasurable orders the stability at the equilibrium point can be investigated by the characteristic equation $\operatorname{det}\left(\lambda^{\gamma} \mathrm{I}-\mathrm{J}\right)=0$ for $\gamma=1 / m$ where $m$ is the LCM of the denominators of $u_{i}$, if $q_{i}=v_{i} / u_{i}, v_{i}, u_{i} \in Z^{+}$ and the stability condition meets $|\arg (\lambda)|>$ $\gamma \pi / 2$.

All six systems were evaluated under the same integration step size conditions. $h=0.005$ and simulation time $T_{\text {sim }}=100 \mathrm{~s}$. The algorithms were programmed with Matlab R2019a, in double precision, the type of rounding error and machine epsilon of $2.2204 \mathrm{e}-$ 16 , a list of parameters used for the simulation of the systems applying the GL and ABM algorithm are given in the Table 2 .

\begin{tabular}{|c|c|c|c|}
\hline & Coefficients & $\begin{array}{c}\text { C. I. } \\
x(0), y(0), z(0)\end{array}$ & Fractional order \\
\hline (1) & $\sigma=10, \rho=28, \beta=8 / 3$ & $(0.1,0.1,0.1)$ & $\alpha_{1}=\alpha_{2}=\alpha_{3}=0.995$ \\
\hline (2) & $\mathrm{a}=0.5, \mathrm{~b}=0.2, \mathrm{c}=10$ & $(0.5,1.5,0.1)$ & $\begin{array}{l}\alpha_{1}=0.9, \alpha_{2}=0.85, \alpha_{3} \\
-0 \mathrm{n}\end{array}$ \\
\hline (3) & $\mathrm{a}=1.0, \mathrm{~b}=0.1, \mathrm{c}=1.0$ & $(2,-1,1)$ & $\alpha_{1}=\alpha_{2}=\alpha_{3}=0.9$ \\
\hline (4) & $a=e=1, b=2.5$ & $(0.2,0,0.5)$ & $\alpha_{1}=1.0, \alpha_{2}=0.9, \alpha_{3}$ \\
\hline (5) & $a=35, b=3, c=28, d=-7$ & $(-9,-5,14) \mid$ & $\alpha_{1}=\alpha_{2}=\alpha_{3}=0.9$ \\
\hline (6) & $\mathrm{a}=36, \mathrm{~b}=3, \mathrm{c}=20$ & $(0.2,0.5,0.3)$ & $\begin{array}{l}\alpha_{1}=0.98, \alpha_{2}=0.99, \alpha_{3} \\
=0.98\end{array}$ \\
\hline
\end{tabular}

Table 2 Parameters used in the simulations of the 6 attractors of fractional order

The results of the numerical simulation applying the definition of Grünwald-Letnikov are given in Figures 1 and 6 respectively, where the creation of a chaotic oscillator sensitive to the initial conditions is shown.
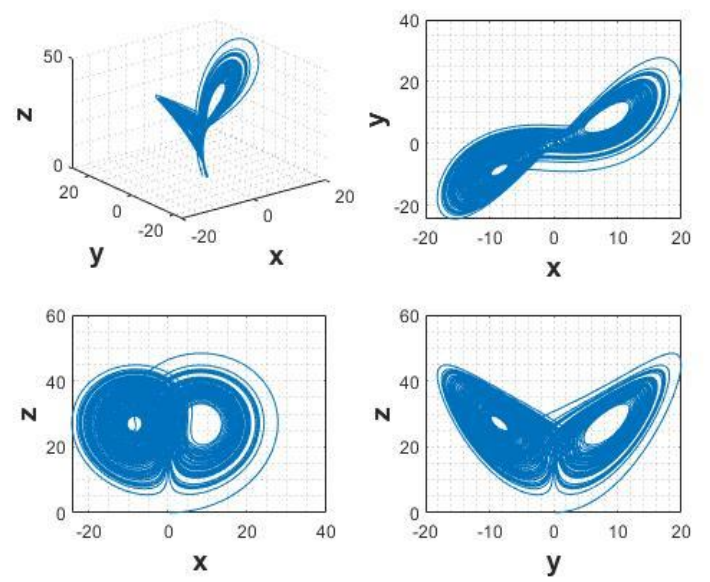

Figure 1 Results of the numerical simulation in 3D, xy, xz and yz planes respectively of the Lorenz system, applying GL
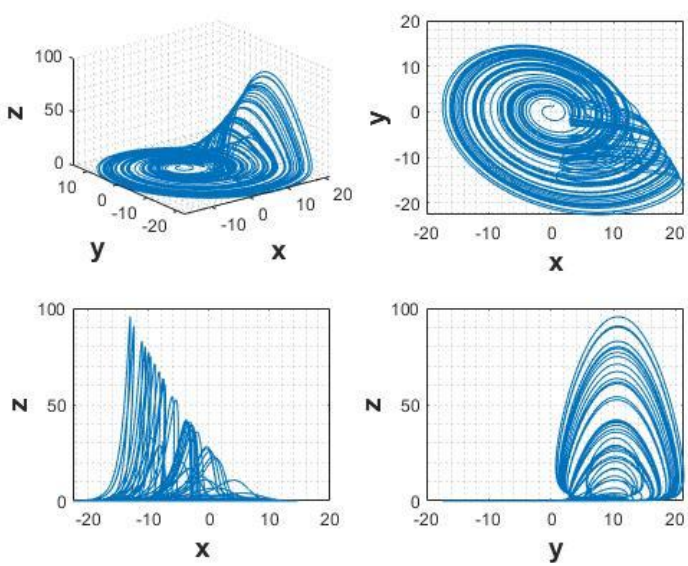

Figure 2 Results of the numerical simulation in 3D, xy, xz and yz planes respectively of the Rössler systems, applying G-L
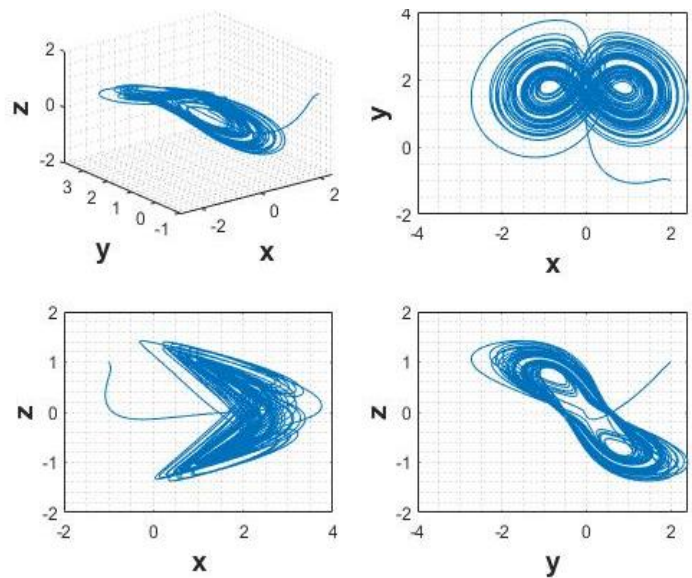

Figure 3 Results of the numerical simulation in 3D, xy, xz and yz planes respectively of the Financial system, applying GL 

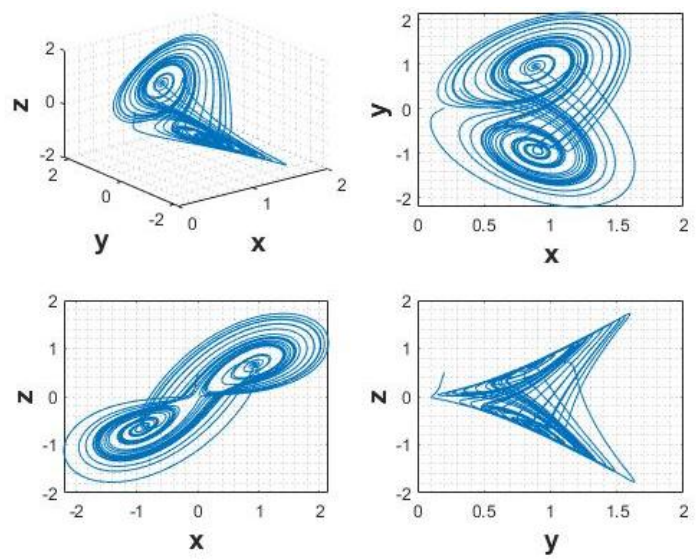

Figure 4 Results of the numerical simulation in 3D, xy, $x z$ and yz planes respectively of the Liu systems, applying G$\mathrm{L}$
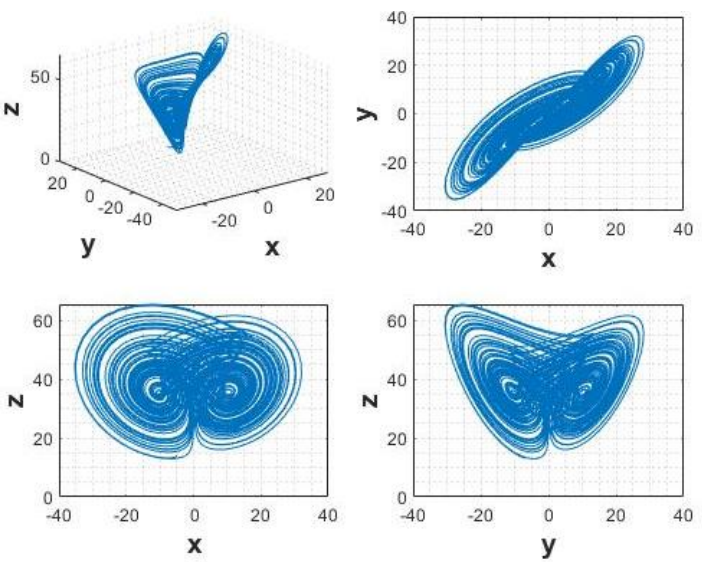

Figure 5 Results of the numerical simulation in 3D, $\mathrm{xy}, \mathrm{xz}$ and yz planes respectively of the Chen system, applying G-L
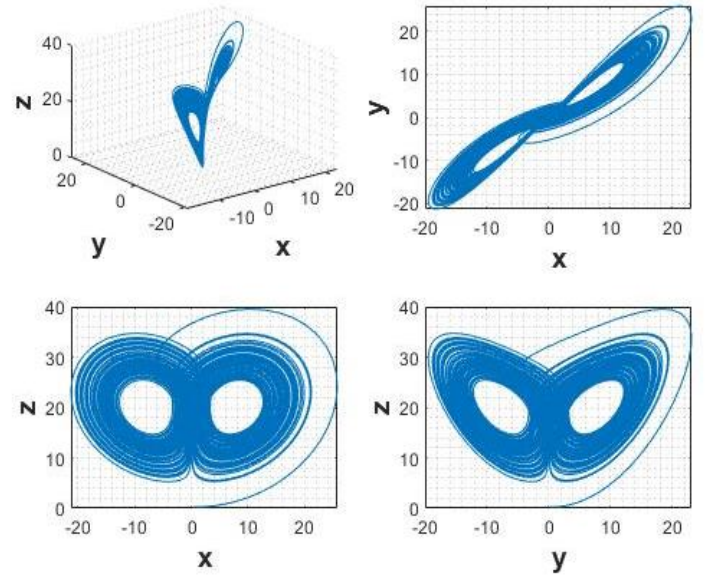

Figure 6 Results of the numerical simulation in 3D, $x y, x z$ and yz planes respectively of the Lü system, applying G$\mathrm{L}$

Similar to the previous one, the six chaotic systems of fractional order that are analyzed in this work for the Adams-BashforthMoulton method are adapted with the PredictorCorrector scheme.
This method is suitable because it only requires the initial conditions and for the unknown function it has a clear physical meaning since it is consistent with the Grünwald-Letnikov method, as well as the Caputo, Riemman Louville and FDE12 method..
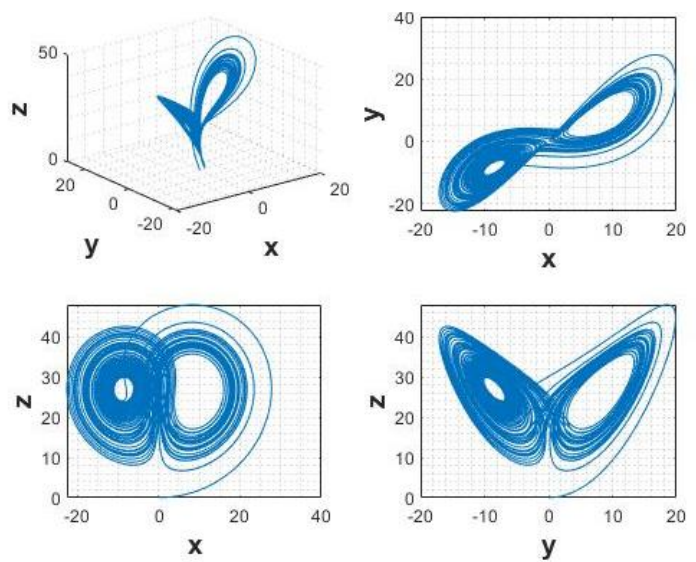

Figure 7 Results of the numerical simulation in 3D, xy, $x z$ and yz planes respectively of the Lorenz system, applying $\mathrm{ABM}$
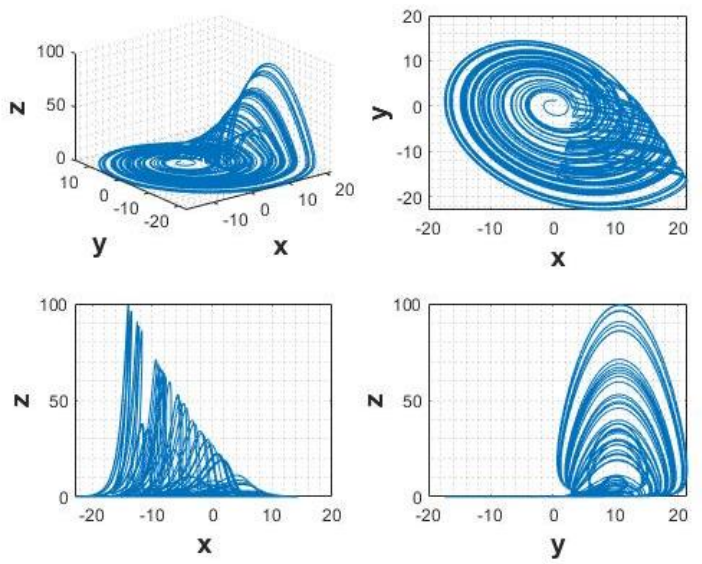

Figure 8 Results of the numerical simulation in 3D, xy, xz and yz planes respectively of the Rössler system, applying $\mathrm{ABM}$
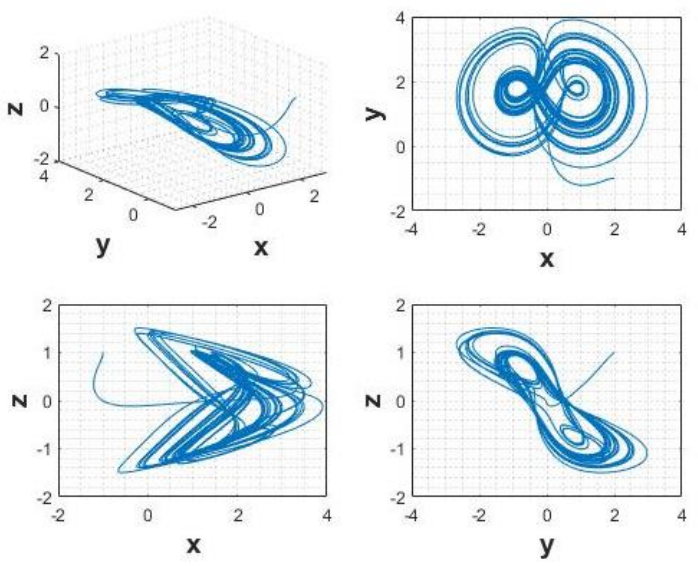

Figure 9 Results of the numerical simulation in 3D, xy, xz and yz planes respectively of the Financial system, applying ABM

SILVA-JUÁREZ, Alejandro, SALAZAR-PEDRAZA, Miguel De Jesús, PONCE-MELLADO, Juan Jorge and HERRERA-SÁNCHEZ, Gustavo. Simulation of Chaotic Oscillators of Fractional Order. ECORFAN Journal-Taiwan. 2019 

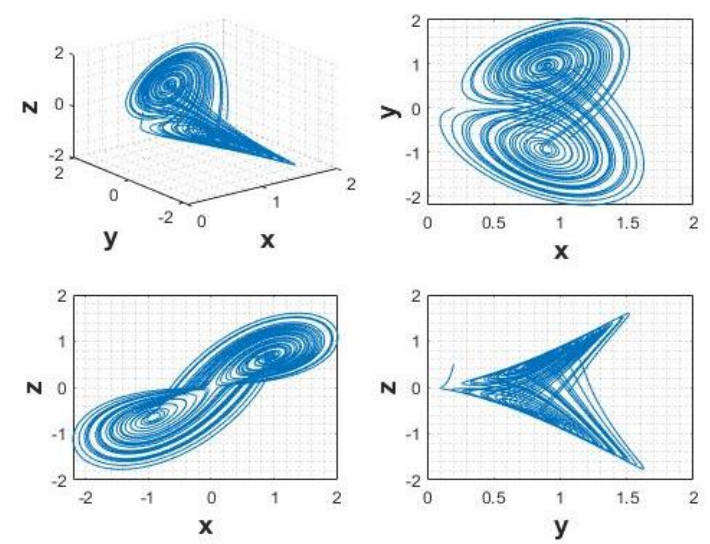

Figure 10 Results of the numerical simulation in 3D, xy, $\mathrm{xz}$ and yz planes respectively of the Liu system, applying $\mathrm{ABM}$
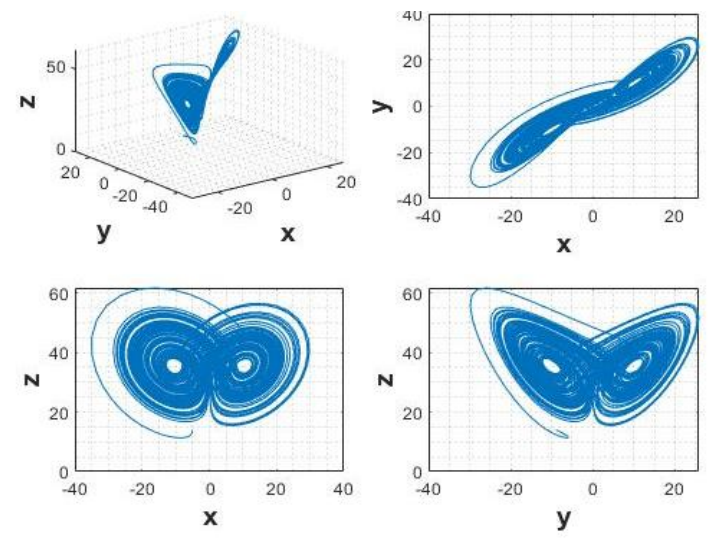

Figure 11 Results of the numerical simulation in 3D, xy, $\mathrm{xz}$ and yz planes respectively of the Chen system, applying $\mathrm{ABM}$
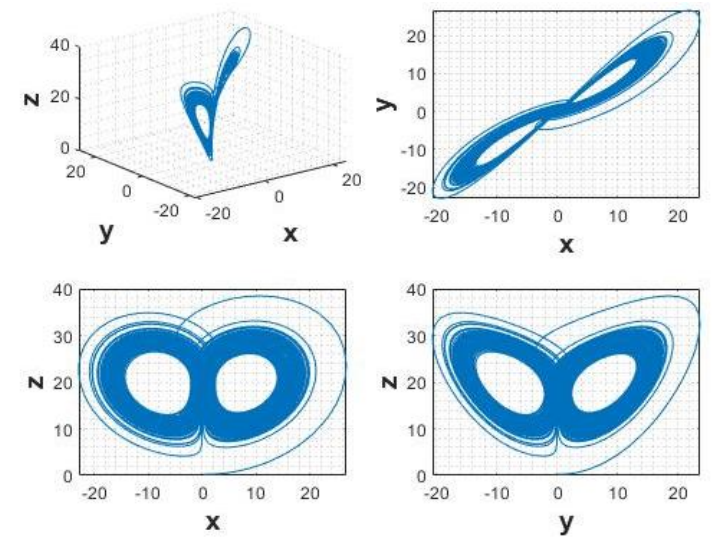

Figure 12 Results of the numerical simulation in $3 \mathrm{D}$, xy, $\mathrm{xz}$ and $\mathrm{yz}$ planes respectively of the Lü system, applying $\mathrm{ABM}$

\section{Conclusions}

The application of the definition of GrünwaldLetnikov and the corrective predictor method of Adams-Bashforth-Moulton to simulate chaotic oscillators of a fractional order have been shown. Stability conditions for commensurate and immeasurable systems were considered for this.
The results of both methods provide the numerical approximations of the solution of the differential equations of fractional order, which implies that they can be implemented in hardware, one of the problems is that both are based on memory use, that is why as future work Implementation differences will be investigated using analog electronics such as FPAA's and digital as FPGA's.

\section{References}

[1] Petráš, I, Fractional-order nonlinear systems: modeling, analysis and simulation, Springer Science \& Business Media, 2011.

[2] SUN, HongGuang, et al. A new collection of real world applications of fractional calculus in science and engineering. Communications in Nonlinear Science and Numerical Simulation, 2018.

[3] K. Diethelm, N. J. Ford, and A. D. Freed. A predictor-corrector approach for the numerical solution of fractional differential equations. Nonlinear Dyn.,29(1):3-22, jul. 2002.

[4] Dorcak, L. (2002). Numerical models for the simulation of the fractional-order control systems. arXiv preprint math/0204108.

[5] Deng W., 2007a, Short memory principle and a predictor-corrector approach forfractional differentional equations, Journal of Computational and Applied Mathematics, 206, 174-188.

[6] K. B. Oldham and J. Spanier. The Fractional Calculus, Theory and Applications of Differentiation and Integration to Arbitrary Order. Dover Publications, Inc., 2002.

[7] Podlubny I., 1999, Fractional Differential Equations, Academic Press, San Diego.

[8] Ford N. and Simpson A., 2001, The numerical solution of fractional differential equations: speed versus accuracy, Num. Anal. Report 385, Manchester Centre for Computational Mathematics. 
[9] Pham, V. T., Kingni, S. T., Volos, C., Jafari, S., \& Kapitaniak, T. (2017). A simple threedimensional fractional-order chaotic system without equilibrium: Dynamics, circuitry implementation, chaos control and synchronization. AEU-International Journal of Electronics and Communications, 78, 220-227.

[10] Tavazoei, M. S., \& Haeri, M. (2007). A necessary condition for double scroll attractor existence in fractional-order systems. Physics Letters A, 367(1-2), 102113.

[11]Tacha, O. I., Munoz-Pacheco, J. M., Zambrano-Serrano, E., Stouboulos, I. N., \& Pham, V. T. (2018). Determining the chaotic behavior in a fractional-order finance system with negative parameters. Nonlinear Dynamics, 1-15. 